\title{
Editorial
}

\section{The role of health promotion in poverty reduction}

Haifa Husni Madi ${ }^{1}$ and Syed Jaffar Hussain ${ }^{2}$

\section{Introduction}

Debate around poverty and health has been going on for decades. More central to this debate in recent times is the argument whether poverty leads to ill-health, or poor health is a precursor of poverty. Although ample scientific evidence currently supports both arguments, the fact remains the same: poverty and ill-health almost always co-exist.

In recent years, governments and development partners have placed greater focus on addressing the determinants of health. Health promotion, as defined in the Ottawa Charter in 1986, has been shown to be an important element of public health [1]. By virtue of this phenomenon, health promotion has been shown to address the "causes of the causes" of health, thereby improving the health of the population. The nexus of health and poverty has also been reinforced in the United Nations Millennium Development Goals. The importance of these goals in health is, in one sense, self-evident. Improving the health and longevity of the poor is an end in itself - a fundamental goal of economic development. But it is also a means to achieving the other development goals relating to poverty reduction [2]. The linkages of health to poverty reduction and to long-term economic growth are powerful, much stronger than is generally understood.
Even in the most affluent countries, people who are less well off have substantially shorter life expectancies and more illnesses than the rich. Not only are these differences in health an important social injustice, they have also drawn scientific attention to some of the most powerful determinants of health standards in modern societies [3].

This paper frames a debate around the nexus between ill-health and poverty and articulates the various dimensions of health promotion, viz. exploring the dynamics of how health promotion interventions can be relevant in poverty reduction, and thus improving the health of the population.

\section{Framing the debate}

The definition of health promotion as outlined in the Ottawa Charter is "Health promotion is the process of enabling people to increase control over, and to improve, their health". To reach a state of complete physical, mental and social well-being, an individual or group must be able to identify and to realize aspirations, to satisfy needs, and to change or cope with the environment. Health is, therefore, seen as a resource for everyday life, not the objective of living. Health is a positive concept emphasizing social and personal resources, as well as physical capacities. Therefore, health pro-

${ }^{1}$ Director of Health Protection and Promotion; ${ }^{2}$ Regional Adviser for Health Promotion and Injury Prevention, WHO Regional Office for the Eastern Mediterranean, Cairo, Egypt (Correspondence to Syed Jaffar Hussain: hussains@emro.who.int).

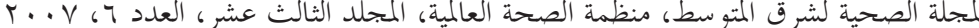


motion is not just the responsibility of the health sector, but goes beyond healthy lifestyles to well-being [1]. This definition has been amplified in practice and has been the subject of 6 global conferences. To many, the Ottawa charter for health promotion became the gospel and foundation stone of a new public health movement [4].

In many parts of the world, health promotion goals and processes are firmly embedded in national and multinational health policies, objectives and targets. The focus of health promotion on the prerequisites for health and equity in health is recognized nationally and globally through the Millennium Development Goals and other policies to address social and economic determinants of health and inequalities in health. The Ottawa Charter's call to work in partnership with other sectors to develop healthier public policy has been widely adopted and implemented. This has taken shape in various ways, reflecting social, cultural and economic contexts and the stage of development of health promotion practice [5].

The number of people living in absolute poverty and despair is growing steadily despite unprecedented wealth creation worldwide in the past 2 decades. Today nearly 1300 million people live in absolute poverty [6]. Poverty is a major cause of ill-health; it contributes to the spread of disease, undermines the effectiveness of health services and slows population control. Morbidity and disability among poor and disadvantaged groups lead to a vicious spiral of marginalization, to their remaining in poverty, and in turn, to increased ill-health. In the past, spending on health and health programmes was considered to be expenditure on welfare and welfare programmes. It was thought that economic growth would make more resources available to health systems and that as a result health outcomes would improve. This has, however, proven not to be an automatic process [7]. Moreover, studies in recent years have shown that improvements in health contribute significantly to economic growth.

Health is a continuum that ranges from the healthy, unexposed population through to the population that suffers from specific diseases and their consequences. Health promotion incorporates both upstream approaches (aiming to improve the contexts for health generation, improving social capital and community capacity to act on health) as well as downstream actions (risk reduction through behaviour change communication, promotion of self-help in disease and coping with the consequences of disease).

The focus is on upstream approaches, with the Bangkok charter for health promotion in a globalized world [8] identifying actions and commitments in 4 areas:

- the global development agenda

- whole-of-government approaches

- action by communities and civil society

- health promotion as an integral part of good corporate practice.

\section{The nexus between poverty and health}

Health is unevenly distributed among social groups in the population. We have to acknowledge that we live in a stratified society, where the most privileged people, in economic terms, have the best health. These inequalities in health are socially determined, unfair and modifiable. At the same time there has been a paradigm shift in the perception and vocabulary of development in recent years. Where once development was equated with economic 
growth, which was seen as the ultimate goal, now poverty reduction is seen as the overarching achievement of development. Where the route to economic growth was once seen as running through investment in physical capital, it is now recognised that many forms of capital, including human and social capital, contribute to the growth of output [9]. Poverty itself is recognised as a multifaceted concept, not simply a matter of insufficient income, but also a matter of insufficient or inappropriate earning capacities in relation to ill health, ignorance, and lack of power and voice. Where once it was assumed that the benefits of economic growth would eventually "trickle down" to the poor, the delivery of welfare to the poor in the forms of improved livelihoods, social services, and benevolent governance is now seen as both a direct assault on those multiple deprivations and as an investment in the capacities of the poor to lift themselves out of poverty.

Economic growth is still perceived as desirable, but it is for its instrumental value in enhancing the resource base to deliver social services, productive employment opportunities and better governance, not as an end in itself.

As Williamson says, "poverty is...a complex phenomenon rooted in an array of factors and conditions, many of which extend beyond the control of the health sector" [10]. Poverty reduction is not a feature that can be accomplished by any one person in any one sector because poverty is multi-faceted and deeply rooted in many socioenvironmental conditions. It calls for a community-based, multisectoral approach. The nexus between poverty and health is best articulated in Figure 1.

At a purely material level, income has an obvious impact on health insofar as it provides the means of obtaining the fundamental prerequisites for health such as shelter, food, warmth and the ability to participate in society. Low income, therefore, increases individuals' exposure to harmful environments, e.g. inadequate housing, and reduces a family's ability to purchase necessities such as a healthy diet. Poverty also reinforces health-damaging behaviours [11].

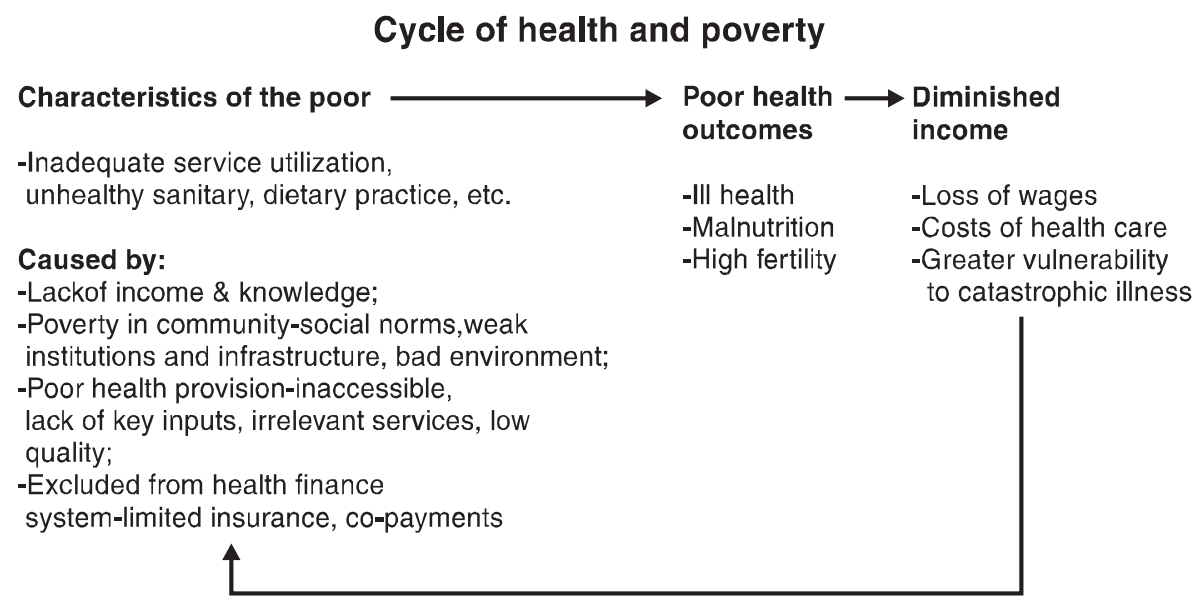

Figure 1 Cycle of health and poverty, source: Claeson M et al. [13]

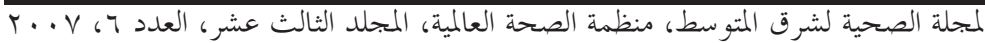




\section{The place of health promotion in poverty reduction}

Health promotion is a basic building block of public health. Together with population health assessment, health surveillance, disease and injury prevention, and health protection, health promotion is a central public health function that furthers all public health work. Health promotion and disease and injury prevention can be approached by addressing individual risk factors for specific health outcomes (e.g. poor nutrition, physical inactivity, excessive sun exposure) or by addressing the underlying societal risk conditions (e.g. poverty and socioeconomic-related linked inequities) [12]. For many years, the international health community has been pointing to the large gaps in health outcomes between rich and poor countries. Extensive scientific evidence is now available on the factors that contribute to good health outcomes in childhood, the reproductive period and adulthood. For example, much is known about preventive and curative health services that promote good health among small children, sound dietary and sanitary practices and the importance of stimulation for young children [13].

Health-along with education-is seen as one of the key ultimate goals of development. Indeed, increasingly health is seen as a dimension of poverty in its own right. This is reflected in the fact that no less than 4 of the 7 Millennium Development Goals relate to health broadly defined. The role that health promotion can play in combating poverty is based on 3 essential components, namely:

- definition and implementation of priority interventions and health services, taking into account the major causes of morbidity and mortality among the poor;
- reinforcement and extension of health systems to provide better management of poor communities by increasing the budget of ministries of health and using their resources more effectively;

- strengthening inter-sectoral collaboration for the benefit of the poor in order to have a positive impact on the key determinants (education, employment, nutrition, participation of the poor in decision-making).

Priority interventions aimed at reducing poverty must be based on certain major principles such as equity and ethics, relevance of health interventions to the needs of the poor, accessibility, quality, efficiency and sustainability, participation of communities concerned, and the taking into account of gender specificity.

Interventions may comprise actions aimed at improving health through the intensification of the fight against practices harmful to health, tuberculosis, maternal and child mortality, tobacco use, malnutrition and HIV/AIDS, and also through immunization, education, environmental health and clean water supply.

A common claim that is incessantly reiterated in health promotion is lack of resources. There is a broadly held belief that economically poor countries have far fewer resources than others with which to engage in interventions to promote health. Moreover, this issue of resources seems to be a feature that distinguishes the practice of health promotion in the economicallydeveloped world from that carried out in the economically-poor world. This may not, however, accurately represent the situation. The argument can surely be made that resources are more than purely financial, and that communities throughout the world have many different kinds of resources with which to support and carry out interventions 
that are health promoting. In fact, an entire area of research and practice has arisen on how to recognize, foster and benefit from assets for health promotion. Nonetheless, in terms of visibility of health-promoting interventions, financial resources seem to be the cornerstone for subsistence and dissemination. It is, however, the case that quite often there are important and critical interventions occurring in the less economically developed world that are indeed effective, but these are not seen because the financial issues associated with evaluation, publication, diffusion, etc. are not available. The assumption that there are noteworthy and vital effective interventions occurring in the developing world has come to be an accepted belief among many in the field of health promotion [14].

\section{Discussion and conclusion}

Many factors play a part in creating and perpetuating social inequalities in health. The situation is complex, but we can nevertheless state that it is generally social circumstances that affect health and not the other way round. Although in many cases serious health problems lead to loss of income and work and difficulties completing education, social status still has a bigger impact on health than health does on social status.

The Ottawa Charter formally recognized that health services should incorporate health promotion concepts such as community development, empowerment and advocacy, and called upon the health sector to move in this direction. The charter states that "... the health sector must move increasingly in a health promotion direction, beyond its responsibility for providing clinical and curative services". The charter provides logic and order to health promotion. It also discusses normative approaches to managing and improving health at individual, community, national and global levels [15]. The commonplace of arguing for the place of health promotion in poverty reduction clearly has convergent theoretical foundations. They refer to the need to work "upstream", to address the "causes of the causes". They are founded on strong ideology and have complementary evidence bases. They recognize the need to operate on social structures, to involve non-health sectors and indeed to base the emphasis of their work on "whole-of-government" commitment. Together, these areas demonstrate the scope, breadth and depth of actions that governments and society as a whole must undertake in order to achieve better health outcomes. Indeed, a key challenge for a unified approach to these areas would be to demonstrate what it would take for public health to navigate complex social and political processes that are driving the way in which health and resources for health are distributed.

Convergence, though, is not identity. The juxtaposition of the work of these fields raises a number of areas of difference such as those outlined below (World Health Organization, unpublished report, 2007). The following scenarios are simplified versions of actual situations that demonstrate the different contributions to be made within a unified structure that addresses all the determinants of health:

- Burden versus gradient-How are policy-makers to reconcile efforts to improve the public health situation of the population generally (e.g. broad improvements in nutritional status) with the observation that this may be associated with worsening inequity (as better-off social classes get proportionally greater improvement)? Broad improvements, the population approach to prevention, may

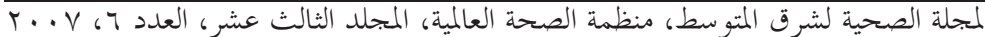


need to be balanced against high-risk approaches (intensive targeted prevention for the poorest classes). But how are we to develop an investment framework for such activities?

- Conflict of interest-A soft drinks company mini-sizes its products (sells it in small bottles priced at a level affordable by poorer families) and uses microfinance strategies to ensure a distribution mechanism that extends to the farthest reaches of the poorest shanty towns. Is this an example of a pro-poor initiative offering a way out of poverty and generation of small businesses? Or is it an example of cynical marketing designed to maximize sales while diverting poor families' incomes into the purchase of "empty" nutrients?

- Side-effects of structural interventions-Raising people out of poverty has an energy cost. If poorer countries develop via the use of environmentally unsound technologies, then the net effect of massive poverty alleviation programmes could contribute to intolerable global warming. For instance, biofuels, which supposedly have a neutral effect on the environment and promote income for poorer countries that export the raw materials (e.g. palm oil), have recently been documented as causing widespread environmental degradation as slash and burn agricultural techniques and clearance of peat areas are adopted to make way for increased palm oil production [16].

- Priority setting - Consider this scenario for a community which has a significant burden of chronic respiratory diseases. Most of the burden is due to tobacco smoking, concentrated in the richer parts of this middle-income country. A smaller portion of the burden is caused by indoor air pollution which is concentrated in the poorest segments of the population. Clearly, both are issues that need addressing, but capacity is limited and local public health officials need guidance on whether to primarily invest in tobacco control (the traditional public health approach) or in promotion of safer fuels (a primarily equity-based strategy).

That being said, fair distribution of resources is a good public health policy [17]. The primary goal of future public health work is not to further improve the health of the people who already enjoy good health: the challenge now is to bring the rest of the population up to the same level as the people who have the best health-levelling up.

In conclusion, it may be argued that health promotion has an in-built survival kit since it deals not only with disease prevention, but the changing or promotion of conditions within which health can thrive [18]. Health promotion seeks to promote conditions supportive of health improvement, and for this reason both the developed and developing countries must cooperate to ensure that the discipline is well established in the latter. All policymakers and programme managers are keen to see better health outcomes for the populations they serve. Better health outcomes are achieved through well-functioning health systems, characterized by good governance, adequate and fair financing, optimal distribution of resources and accessible services, priority health programmes targeting problems that are responsible for the major burden of diseases, and promotional components that tackle the upstream health determinants [19]. 


\section{References}

1. Ottawa charter for health promotion. Geneva, World Health Organization, 1986.

2. Macroeconomics and health: investing in health for economic development. Report on the Commission on Macroeconomics and Health. Geneva, World Health Organization, 2001.

3. Wilkinson R, Marmot M, eds. Social determinants of health: the solid facts, 2nd ed. Copenhagen, World Health Organization Regional Office for Europe, 2003.

4. De Leeuw E, Tang KC, Beaglehole R. Ottawa to Bangkok-health promotion's journey from principles to 'glocal' implementation. Health promotion international, 2006, 21(suppl. 1):1-4.

5. Shaping the future of health promotion: priorities for action. Vancouver, International Union for Health Promotion and Education \& Canadian Consortium for Health Promotion and Health, 2007.

6. Povety reduction and the World Bank: progress and challenges in the 1990s. Washington DC, World Bank, 1996.

7. Can we achieve MDGs by 2015? Report of Millennium Development Goals Costa Rica meeting, 11-13 November 2004. Cairo, World Health Organization Regional Office for the Eastern Mediterranean, 2004.

8. The Bangkok charter on health promotion in a globalized world. Adopted at the 6th Global Conference on Health Promotion, Bangkok, August 2005 (http://www.who. int/healthpromotion/conferences/6gchp/ bangkok_charter/en/, accessed 12 September 2007).

9. Regional strategy on poverty reduction and sustainable development. Cairo, World Health Organization Regional Office for the Eastern Mediterranean, 2003 (EM/RC50/INF.DOC.6).

10. Williamson, D. The role of the health sector in addressing poverty. Canadian journal of public health, 2001, 92(3):178283.

11. Judge K, Paterson I. Poverty, income inequality and health. Wellington, New Zealand, New Zealand Treasury, 2001 (Treasury working paper 01/29).

12. Health promotion as a means to strengthen public health: considerations for Ontario's 2006 public health guideline review. Ontario, Canada, Ontario Prevention Clearinghouse, 2006.

13. Claeson $M$ et al. Poverty-reduction and the health sector. In: Poverty reduction strategy sourcebook. Washington DC, World Bank, 2001.

14. McQueen DV, Jones CM. Global perspectives on health promotion effectiveness. New York, Springer, 2007.

15. Frankish J, Moulton G, Gray D. Health promotion in primary care settings: a suggested approach to establishing criteria. Vancouver, Canada, Institute of Health Promotion Research, University of British Columbia, 2000.

16. Rosenthal E. Scientists are taking 2nd look at biofuels. International Herald Tribune, 31 January 2007 (http://tinyurl.com/ 2hgctz, accessed 25 September 2007).

17. National strategy to reduce social inequalities in health. Oslo, Norway, Ministry of Health and Care Services, 2007 [Report No. 20 (2006-2007) to the Storting].

18. Nyamwaya D. Impediments to health promotion in developing countries: the way forward. Health promotion international, 1996, 11(3):175-6.

19. Tackling health inequities through action on the social determinants of health. Cairo, WHO Regional Office for the Eastern Mediterranean, Commission on Social Determinants of Health, 2007 (Policy brief No. 1).

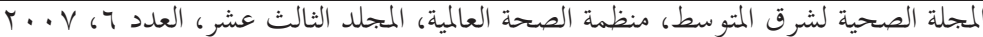

